\title{
Trabalhonecessário
}

Issn: $1808-799 X$

ano 14, número $24-2016$

\section{O PROGRAMA MULHERES MIL E O COOPERATIVISMO NO BRASIL}

Liliane Bordignon $^{1}$

\section{Resumo}

O objetivo do artigo é analisar o desenvolvimento do Programa Mulheres Mil em face do cooperativismo no Brasil. O programa é promovido pelo governo federal e foi elaborado em parceria com a Associação de Collèges Comunitários do Canadá (ACCC). Oferece cursos de qualificação profissional tendo como finalidade: promover a inclusão de mulheres pobres na educação profissional; aumentar a escolarização; inseri-las no mercado de trabalho; e incentivar o "empreendedorismo". As análises de documentos oficiais e as entrevistas com responsáveis pelo programa na ACCC informam que os cursos oferecidos estão mais direcionados para a organização de cooperativas e o empreendedorismo do que para a qualificação profissional com aumento da escolaridade. No entanto, o programa não oferece a estrutura adequada para tanto, como apoio técnico, financeiro e um plano de continuidade do programa. Após a conclusão do curso, as mulheres se desvinculam e perdem a bolsa de estudos, o que pode limitar o retorno a escolarização e mesmo a organização de cooperativas.

Palavras chave: Programa Mulheres Mil, qualificação profissional e cooperativismo

\section{Resumen}

El objetivo del artículo es analizar el desarrollo del Programa de Mulheres Mil en relación al movimiento cooperativo en Brasil. El programa es patrocinado por el gobierno federal y se ha desarrollado en colaboración con la Asociación de

1 Doutoranda no Programa de Pós-graduação em Educação - FE - Unicamp. Contato: lilianebordignon@yahoo.com.br. 


\section{Trabalhonecessário}

Issn: $1808-799 X$

ano 14, número $24-2016$

Collèges Comunitarios de Canadá (ACCC). Ofrece cursos de formación profesional y tiene como objetivo: promover la inclusión de las mujeres pobres en la educación; aumentar la matrícula; insertarlas en el mercado laboral; y promover el "empreendedurismo" El análisis de los documentos oficiales y entrevistas con los responsables del programa en la ACCC ha informado de que los cursos que se ofrecen estan más orientadas a la organización de cooperativas y el "empreendedorismo" que a la calificación profesional con una mayor escolaridad. Sin embargo, el programa no proporciona el marco adecuado para este propósito, tales como el plan técnico, financiero y de la continuidad del programa. Al finalizar el curso, las mujeres se desenganchan y pierden la beca, lo que puede limitar el regreso a la escuela e incluso la organización de cooperativas.

Palabras clave: Programa Mulheres Mil, cualificación profesional y cooperativismo.

\section{Introdução}

O objetivo deste trabalho é analisar o Programa Mulheres Mil e suas relações com a organização de cooperativas de mulheres no Brasil. $O$ trabalho tem origem na pesquisa Relações entre a expansão do ensino técnico no Brasil e os projetos de cooperação internacional com o Canadá, realizada em 2012. Durante a pesquisa analisamos a legislação que regulamenta o programa e as orientações do Ministério da Educação (MEC) para o seu desenvolvimento. Realizamos entrevistas com profissionais da Associação de Collèges Comunitários do Canadá (ACCC), responsáveis pelos acordos internacionais, assim como com profissionais de instituições que oferecem educação profissional em Montreal/Québec e sindicalista da Federação Nacional de Professoras e Professores do Québec (FNEEQ).

O Programa Mulheres Mil tem como objetivo oferecer cursos de qualificação profissional para mulheres comprovadamente em situação de 


\section{Trabalhonecessário}

Issn: $1808-799 X$

ano 14, número $24-2016$

pobreza, financiados por bolsa de estudos. Durante os cursos, o programa procura incentivar as mulheres a se organizarem em cooperativas populares, atendendo as demandas econômicas regionais e incentiva o retorno à escolarização. Constatamos que os cursos possuem tempo determinado de duração, aproximadamente um ano e não apresenta um projeto de continuidade da formação para as mulheres envolvidas, assim como não oferece apoio técnico e financeiro para a organização de cooperativas ao término do curso. Com isso, delega exclusivamente às mulheres a "continuidade" dos objetivos contidos no programa: escolarização e formação de cooperativas de trabalho.

Apresentaremos a seguir um panorama do Programa Mulheres Mil a partir de dados levantados na pesquisa e uma análise sobre as relações que se estabelecem entre formação para o trabalho e cooperativismo no escopo deste programa.

\section{PROGRAMA MULHERES MIL: EDUCAÇÃO, CIDADANIA E DESENVOLVIMENTO SUSTENTÁVEL}

O Programa [Mulheres Mil] pretende ampliar o atendimento, garantindo 0 direito à educação, oportunidade de melhoria de renda por meio do acesso ao trabalho decente. Assim, contribuirá para reduzir os índices de miséria e pobreza, para elevar os níveis educacionais e impulsionar o desenvolvimento econômico e social do País, com mais equidade e justiça social (Programa Nacional Mulheres Mil).

O Programa Mulheres Mil é desenvolvido no interior de diferentes campi dos Institutos Federais de Educação, Ciência e Tecnologia (IFs). Foi iniciado em 2007, por meio de um projeto piloto que envolveu treze Institutos Federais da região Norte e Nordeste do país, oferecendo cursos de qualificação profissional para mil mulheres em situação de pobreza.

A iniciativa foi antecedida por outro projeto menor, realizado pela parceria entre o Niagara College e o Instituto Federal do Rio Grande do Norte (IFRN), em 


\section{Trabalhonecessário}

Issn: $1808-799 X$

ano 14, número $24-2016$

2005. O principal objetivo da parceria era possibilitar o retorno à escolarização da população de baixa renda por meio dos Institutos Federais, que naquele período ainda eram Centros Federais de Educação Tecnológica.

No interior do primeiro projeto, professores dos IFs selecionados realizaram uma formação específica para desenvolver um trabalho de inclusão social com mulheres pobres utilizando o método de Avaliação e Reconhecimento de Aprendizagem Prévia (ARAP). A formação foi realizada pela ACCC, como podemos observar no depoimento de Jos Nolle, diretor de desenvolvimento do Niagara College.

[Inicialmente], Marti Jurmain [docente do Niagara College] deu o treinamento [de reconhecimento de competências] para os professores [brasileiros], e propusemos que eles fossem às comunidades e selecionassem mulheres, sem educação formal, mas que tivessem experiência de vida e de trabalho (...). Fechamos este projeto em 2005, com a cerimônia de graduação de 60 mulheres de Natal e apresentação de outras cidades sobre os seus grupos (BRASIL, 2011a, p.14).

O projeto piloto desenvolveu um curso de qualificação profissional na área de turismo, na cidade de Natal/RN. Segundo Marti Jurmain, ao final do projeto em turismo foi averiguado se havia interesse dos profissionais de determinados IFs em participar de um novo projeto de um ano com a Avaliação e Reconhecimento da Aprendizagem Prévia (ARAP) (BRASIL, 2011a, p.17).

Durante a formação dos gestores e demais profissionais dos Institutos Federais para a realização do programa de reconhecimento de competências, cada IF se associou a um collèges canadense por proximidade de área de formação. Um exemplo: o Instituto Federal do Ceará se associou ao Niagara Collège e ao Collège Montmorrency na área de turismo, e durante um período trabalhou em colaboração com as referidas instituições para o desenvolvimento do sistema de reconhecimento de competência no campo do turismo.

A diretora da ACCC no setor de parcerias internacionais, quando indagada sobre as origens das parcerias entre Brasil e Canadá por meio da ACCC, afirmou 


\section{Trabalhonecessário}

Issn: $1808-799 X$

ano 14, número $24-2016$

em entrevista ${ }^{2}$ que o Programa Mulheres Mil foi originado no desenvolvimento do projeto School to school conections, no interior de alguns CEFETs, no final da década de 1990. O objetivo daquele projeto era a informatização de escolas em parceria com empresas da região. O programa foi financiado pela Agência Canadense de Desenvolvimento Internacional (ACDI).

Segundo a diretora, o programa School to school conections foi cancelado pelo governo canadense sob o argumento de que o Brasil já não precisava do mesmo apoio financeiro aos seus projetos, considerando a conjuntura social e econômica do período. Em meio às discussões sobre o encerramento do programa, a ACCC propôs o desenvolvimento de outro projeto voltado especificamente para a região nordeste do país e para as mulheres de baixa renda.

Patrícia Barcelos, diretora de articulação e projetos especiais da secretaria de educação profissional e tecnológica (SETEC/MEC) durante a execução do programa, relatou que o projeto inicial seria realizado apenas na região Nordeste. No entanto, comprovou-se "por meio de dados estatísticos" que o "Norte também era uma região desfavorecida (...) que merecia atenção" (BRASIL, 2011a, p.7). Com esse argumento, a ACDI concordou em colaborar com o financiamento dos primeiros treze subprojetos do Programa Mulheres Mil nas duas regiões.

Desde o início, a proposta era realizar o projeto nos CEFETs, atuais Institutos Federais, considerando que são instituições públicas "elitizadas", nas palavras da diretora da ACCC, o que era um problema a ser solucionado na visão do MEC e seus parceiros internacionais. Portanto, era necessário o desenvolvimento de projetos que também buscassem formas de democratização do acesso aos IFs.

Durante a realização do Programa Mulheres Mil, integrantes do MEC, do Conselho Nacional da Rede Federal de Educação Profissional, Científica e Tecnológica (CONIF), da SETEC e dos IFs realizaram um conjunto de visitas aos

\footnotetext{
2 Entrevista concedida à autora em outubro de 2012.
} 


\section{Trabalhonecessário}

Issn: $1808-799 X$

ano 14, número $24-2016$

collèges canadenses. De acordo com a diretora da ACCC, foi organizada, aproximadamente, uma dezena de visitas de integrantes do MEC. Os profissionais vinculados aos collèges canadenses, por sua vez, visitaram instituições brasileiras em São Paulo e no Rio de Janeiro. A maioria das visitas foi feita no interior dos dois Fóruns Brasil-Canadá de Educação Profissional e Tecnológica.

Para além do Programa Mulheres Mil, as visitas realizadas pelos reitores do IFs aos collèges resultaram em, aproximadamente, cinquenta e um acordos de parceria. O objetivo era incentivar o intercâmbio de estudantes e de profissionais e favorecer o desenvolvimento da pesquisa aplicada em parceria entre as instituições. Portanto, existem os acordos mais gerais, desenvolvidos entre ACCC e MEC, e acordos específicos entre as instituições, pois os collèges são instituições autônomas, como as universidades.

No Canadá, a educação é responsabilidade das províncias, em todos os níveis. Cada uma das treze províncias canadenses possui o seu próprio sistema educacional. No caso do Québec, os Cégeps são as instituições que oferecem o ciclo básico que antecede a entrada na universidade e nos cursos tecnológicos. São instituições autônomas que também acolhem o desenvolvimento de projetos alternativos relacionados a outros níveis da escolarização e outros cursos complementares.

Cabe ressaltar que cada província possui o seu sistema de reconhecimento de competências adquiridas no trabalho (reconnaissance des acquis et des compétences - RAC), e cada instituição realiza o seu próprio processo de reconhecimento de competências. Existe uma orientação nacional, entretanto, as províncias são autônomas para desenvolver seu sistema.

O projeto piloto do Programa Mulheres Mil foi concluído em 2010, finalizando também a parceria entre Brasil e Canadá para o desenvolvimento do programa. Foram oferecidos cursos de qualificação profissional em diferentes áreas, como turismo e gestão. O governo brasileiro transformou o projeto em um programa oficial, integrando-o as ações do Plano Brasil Sem Miséria. Os IFs 


\section{Trabalhonecessário}

Issn: $1808-799 X$

ano 14, número $24-2016$

puderam optar em aderir ou não ao programa. Atualmente o projeto é totalmente financiado pelo governo federal e realizado em diferentes estados.

A portaria que oficializou o programa estendeu a possibilidade do seu oferecimento ao "Sistema S" e a entidades privadas sem fins lucrativos, desde que comprovada experiência no oferecimento da educação profissional. Estabeleceu também que os cursos criados devem ter no mínimo a carga horária de 160 horas. O Ministério da Educação é o responsável pelo financiamento, mas a portaria determina que caso isto não seja possível, as instituições deverão financiar o programa por meio de suas dotações orçamentárias. A portaria também instituiu o Centro de Referência do Programa Mulheres Mil no MEC, responsável pela formação dos gestores para o reconhecimento de aprendizagem prévia.

Em 2011, foi realizada a primeira chamada pública aos Institutos Federais para a participação no Programa Mulheres Mil. No documento em que realiza a chamada, o MEC justifica a extensão do programa às demais unidades da federação da seguinte forma:

\footnotetext{
A proposta apresenta uma metodologia desenvolvida para acolher mulheres que se encontram em diversos contextos sociais de marginalização e vulnerabilidade social e incluí-las no processo educacional e no mundo do trabalho.

Posto que esta realidade não está concentrada exclusivamente nas regiões norte e nordeste, fez-se necessário expandir a iniciativa, transformando-a, assim, em um Programa Nacional (Chamada Pública MEC/SETEC - 01/2011, p.2).
}

Cada instituição interessada enviou um projeto de adesão à SETEC/MEC e indicou dois funcionários para a gestão do programa e realização de curso de formação para "conhecimento e implantação da metodologia Mulheres Mil" (Chamada Pública MEC/SETEC - 01/2011, p.2). O objetivo da primeira chamada era qualificar dez mil mulheres em todo o país, através de cem novos núcleos de execução do programa. Foram implantados noventa e oito novos núcleos em todas as regiões do país. O MEC destinou cem mil reais por campus selecionado para a execução do programa. 


\section{Trabalhonecessário}

Issn: $1808-799 X$

ano 14, número $24-2016$

Em 2012, uma nova chamada pública foi realizada, cuja meta era incluir mais cento e dois campi no programa, com a previsão de cem mulheres atendidas por campus. As condições para a participação, assim como o financiamento e exigências para a execução, continuaram as mesmas da chamada anterior. Somente o número de instituições atendidas foi modificado.

As Chamadas Públicas sustentam que a qualificação profissional pode ser utilizada como um atrativo ao retorno à escolarização, uma vez que as mulheres veem uma utilidade na formação que estão adquirindo. Em diferentes propagandas e documentos do Programa Mulheres Mil sustenta-se que os cursos oferecidos podem representar a inserção real destas mulheres no mercado de trabalho. Podemos citar como exemplo o pronunciamento feito pela presidente Dilma Rousseff, em 2011, no dia das mulheres, no qual afirmou que "o Programa Mulheres Mil está garantindo formação profissional e tecnológica para a inserção de milhares de mulheres no mercado de trabalho até 2014 ".

Observamos que a "inserção no mercado de trabalho" não significa necessariamente contratos formais de trabalho, com o cumprimento dos direitos trabalhistas, podendo representar a inserção em trabalhos precários. O Programa Mulheres Mil, em seu eixo desenvolvimento sustentável, incentiva principalmente o "empreendedorismo, as formas associativas solidárias e a empregabilidade" (Programa Nacional Mulheres Mil) como vias de entrada no mercado de trabalho.

(...) é importante considerar (...) as potencialidades econômicas existentes para detectar a vocação econômica local e, a partir daí, estabelecer parcerias com as entidades e empresas, visando à inserção das educandas no mundo produtivo, por meio de empreendedorismo, associações solidárias, empregabilidade e incubadoras tecnológicas sociais. Como consequência dessa ação, verifica-se que as educandas têm diversas alternativas de mobilidade no mundo do trabalho (Plano Nacional Mulheres Mil).

Outro aspecto do programa que merece atenção é a participação de profissionais dos Institutos Federais. O orçamento do programa não prevê a remuneração destes trabalhadores. A carga horária dedicada ao desenvolvimento do curso é incluída como atividade de extensão, ou seja, na carga horária dos 
Issn: $1808-799 X$

ano 14, número $24-2016$

professores e gestores, configurando uma espécie de "trabalho voluntário", uma vez que depende da adesão dos profissionais ao projeto. Os gestores do programa, assim como assistentes sociais, pedagogos, psicólogos, também não são remunerados para a realização das atividades, portanto, realizam o atendimento no escritório de acesso do Mulheres Mil diariamente, para além das demais atividades demandadas pelo Instituto Federal.

Segundo Patrícia Barcelos, o Programa Mulheres Mil mobilizou os Institutos Federais,

(...) porque as escolas de educação profissional sempre foram muito disputadas. Há um processo seletivo, e os alunos que concorrem têm grande desempenho em provas nacionais e internacionais. E, de repente, elas se depararam com um grupo de mulheres, muitas vezes, analfabetas, que não se veem naquele processo educativo. Por isso as instituições tiveram que desconstruir tudo o que está construído, aquele currículo que já está certinho, a grade de professores organizada, para construir uma nova proposta para o grupo (BRASIL, 2011a, p.8).

Certamente as instituições transformaram sua organização local para receber, aproximadamente, cem mulheres participantes do programa. Não se trata de um número pequeno de estudantes, exigindo organização dos profissionais para a realização do curso. No entanto, observamos que foi pequeno o incentivo à ampliação da infraestrutura da instituição para a recepção deste público, assim como a ausência da remuneração dos profissionais pelo trabalho realizado para a formação das estudantes, que caracterizou o programa como uma espécie de projeto assistencial oferecido por instituições tradicionalmente especializadas no ensino técnico.

Ao final do curso, as participantes do programa recebem um certificado referente à qualificação profissional realizada. Durante o curso, é possível encaminhar as estudantes para o reconhecimento de aprendizagem prévia, por meio da Rede Certific, mas o processo não acontece necessariamente e parece ter se desvinculado das ações do programa. 
Issn: $1808-799 X$

ano 14, número $24-2016$

Observamos que o programa Mulheres Mil incentiva o aumento da escolarização com disciplinas de formação básica no interior do curso de qualificação, como língua portuguesa e matemática. No entanto, isto não significa em si aumento da escolarização, como pretende o projeto. $O$ ingresso em outros cursos no próprio Instituto Federal fica sob a responsabilidade das mulheres, pois não há nenhuma ação posterior a conclusão dos cursos de qualificação profissional que direcionem essas mulheres ao retorno à escolarização. Verificamos que é necessária a realização de pesquisas sobre as egressas do programa, interrogando se e como elas continuaram em cursos dos IFs, como 0 PROEJA e o PROEJA-FIC ou se mantiveram a condição anterior à realização do curso de qualificação profissional, nem mesmo ingressando no mercado de trabalho.

\section{PROGRAMA MULHERES MIL, ECONOMIA SOLIDÁRIA E COOPERATIVISMO NO BRASIL}

O Programa [Mulheres Mil] possibilita que as mulheres moradoras de comunidades com baixo índice de desenvolvimento humano, sem pleno acesso aos serviços públicos básicos, ou integrantes dos Territórios da Cidadania, tenham uma formação educacional, profissional e tecnológica, que permita sua elevação de escolaridade, emancipação e acesso ao mundo do trabalho, por meio de estímulo ao empreendedorismo, às formas associativas solidárias e à empregabilidade (Programa Nacional Mulheres Mil).

O Programa Mulheres Mil também procura incentivar as estudantes a desempenhar o chamado empreendedorismo associado à organização de cooperativas populares. Como observamos no trecho citado acima, o empreendedorismo é compreendido pelos planejadores do programa como um meio para a emancipação e o acesso ao mercado de trabalho. O programa defende que a organização cooperativa de mulheres provoca um impacto em suas comunidades e aumenta a renda das famílias, configurando-se como uma forma de enfrentamento ao desemprego e a situações de extrema pobreza. 
Issn: $1808-799 X$

ano 14, número $24-2016$

Os primeiros resultados de sucesso [do programa] já apontavam para o caminho da institucionalização da experiência como política pública inovadora, na qual a educação e a formação profissional e tecnológica se consolidam como instrumento para a inclusão social, a equidade e o desenvolvimento sustentável de comunidades (Programa Nacional Mulheres Mil).

Como não existem dados sistematizados sobre a situação das mulheres egressas do Programa Mulheres Mil, não é possível discutir as consequências deste incentivo ao empreendedorismo e a organização em cooperativas populares; se as estudantes se associaram ou não como forma de enfrentar 0 desemprego e se a qualificação profissional recebida resultou na melhora da situação de emprego. No entanto, consideramos importante questionar o que subjaz a defesa do empreendedorismo e do associativismo expressos no Programa Mulheres Mil. Com isso, apresentamos brevemente neste tópico algumas notas sobre associativismo e cooperativismo, que contribuem para o entendimento da temática e das consequências destas opções.

Existem diferentes experiências no âmbito da chamada economia solidária, que desencadearam processos de emancipação dos trabalhadores, como no caso das fábricas recuperadas na Argentina e também no Brasil. Entretanto, o trabalho autogestionado em cooperativas pode ser sinônimo de emprego sem direitos, que submete as/os trabalhadores a intensas jornadas de trabalho. A organização das mulheres em cooperativas não significa necessariamente emancipação da mulher e promoção de cidadania, emprego e renda. $O$ trabalho de mulheres em cooperativas de costuras ou de alimentação, por exemplo, muito comuns nos grandes centros do país pode significar muito mais trabalho informal, baixa remuneração e condições precárias de trabalho.

O processo de reestruturação produtiva, decorrente das crises do modelo taylorista/fordista desencadeadas na década de 1970, fez emergir ordinariamente no mundo do trabalho formas precárias de utilização da força de trabalho. Dentre elas, podemos incluir a autogestão em cooperativas. 
Issn: $1808-799 X$

ano 14, número $24-2016$

Tal como a informalidade e seu caráter ambíguo, sua histórica flexibilidade e precariedade, repaginada agora como empreendedorismo, as cooperativas de produção industrial ou de trabalho industrial, no contexto atual, fundamentam-se também em um paradoxo: forma de manutenção de empregos e autonomia dos trabalhadores e forma de rebaixamento de custos empresarias (LIMA, 2006, p.307).

Como aponta Jacob Lima (2006), trata-se de paradoxo, pois, por um lado, pode significar a manutenção do emprego dos trabalhadores em situações como aquela de recuperação de fábricas, que desencadeiam um amplo processo de autogestão com garantia de remuneração e dos direitos dos trabalhadores. Por outro lado, as cooperativas podem significar manutenção do emprego precário, sem direitos sociais e garantidor das altas taxas de lucros das empresas que adquirem seus produtos.

Neste sentido, Márcia Leite (2009), analisando os debates teóricos e experiências em economia solidária e associativismo em âmbito nacional e internacional, assinala que a expansão das experiências associativas emerge em um "contexto de crise generalizada (crise ambiental, de um modo de acumulação, do trabalho assalariado, de uma forma de estar no mundo) ". Portanto, estas "experiências carregam consigo as disjuntivas de risco e possibilidade, de velho e de novo, emergindo como portadoras a um só tempo de um conjunto de potencialidades e limites (LEITE, 2009, p.33)".

Para Jacob Lima (2006) a ideia de organização em cooperativas como forma de enfrentar o desemprego e as mudanças no mundo do trabalho não é um fenômeno recente. Esta forma de organização ganhou força na década de 1970, na Europa, a partir crise do capitalismo.

[Naquele contexto], as cooperativas eram formadas para a preservação de empregos decorrentes do crescente fechamento de fábricas, do desaparecimento de postos de trabalho e se constituíam em formas alternativas de ocupação de trabalhadores (principalmente mulheres) em áreas pouco dinâmicas 


\section{Trabalhonecessário}

Issn: $1808-799 X$

ano 14, número $24-2016$

economicamente. Ou, ainda, a partir de movimentos considerados new age de organizar a vida, ocupar moradias, de organizar cooperativas educacionais, de alimentação saudável, de crédito e outras alternativas percebidas como politicamente corretas, por parcelas da classe média (LIMA, 2006, 307).

Márcia Leite (2009) pondera que foi nos anos 1980, em meio à crise do trabalho assalariado, que os pesquisadores começaram a identificar um conjunto de movimentos sustentados por trabalhadores que perderam seus empregos ou que já trabalhavam na informalidade, cujo objetivo central estava na organização de cooperativas de trabalho ou associações de trabalho autogestionadas. Para a autora, são experiências deste tipo que "vem sendo reconhecidas sob o nome de Economia Solidária" (LEITE, 2009, p. 32).

Segundo Jacob Lima (2006), no Brasil, a organização de cooperativas é ampliada na década de 1990, até então havia casos específicos, como recuperação de fábricas abandonadas e cooperativas de geração de renda, ocorridos em anos anteriores. Márcia Leite (2009, p.42) afirma que até a década de 1980 as experiências de cooperativismo se concentravam no meio rural, para a autora foi no contexto das mudanças decorrentes da intensificação do processo de reestruturação produtiva na década de 1990, assim como a reorganização dos movimentos sociais na década anterior, que intensificaram a organização de cooperativas no país.

Jacob Lima (2006) afirma que a ampliação de cooperativas estava também vinculada à reorganização de empresas e a privatização de áreas estratégicas do serviço público, que incentivaram a criação de cooperativas voltadas à terceirização de alguns setores das empresas. Neste período, a CUT criou a Agência de Desenvolvimento Solidário (1999), configurando uma preocupação dos sindicatos com a emergência deste processo. Alguns governos de estados do Sul do país criaram secretarias de economia solidária, para oferecer uma espécie de suporte a este setor. Em 2003, o governo do Partido dos Trabalhadores corrobora com este movimento com a criação Secretaria Nacional de Economia Solidária, consolidando as iniciativas anteriores (LIMA, 2006, p.307-308). 


\title{
Trabalhonecessário
}

Issn: $1808-799 X$

ano 14, número $24-2016$

Analisando os estudos sobre economia solidária no Brasil, Márcia Leite (2009, p.44-46) afirma que as pesquisas indicam que o conjunto de cooperativas existentes é muito diverso. Coexistem no país, "falsas" cooperativas, criadas especificamente com o objetivo de rebaixar os custos das empresas, bem como "verdadeiras" cooperativas, que se mantém coerente aos princípios autogestionários ou que iniciaram nestas condições e foram perdendo a independência com o tempo.

Nas pesquisas analisadas pela autora aparece como unânime o reconhecimento das dificuldades enfrentadas pelas cooperativas:

\begin{abstract}
Essa visão perpassa toda a bibliografia, abarcando desde os mais céticos até os mais entusiastas das potencialidades do cooperativismo. [Os autores destacam] a defasagem tecnológica, a falta de recursos, a baixa escolaridade dos associados, o uso de mão de obra intensiva, a fragmentação do trabalho, as longas jornadas que exaurem os trabalhadores, as diferenciações na distribuição das retiradas, o pouco compromisso dos trabalhadores com o ideal autogestionário (LEITE, 2009, p.45).
\end{abstract}

Outro aspecto levantado pelas pesquisas é o significado da experiência do trabalho em cooperativas. Embora não seja unânime entre as pesquisas analisadas por Márcia Leite (2009), alguns autores destacam que o trabalho cooperado pode promover relações de trabalho mais democráticas e solidárias, desconhecidas anteriormente pelos trabalhadores. No entanto, como destacada anteriormente, estas experiências são minoritárias.

O Programa Mulheres Mil parece fortalecer esse movimento de organização de cooperativas no país como alternativa ao desemprego, sugerindo que as mulheres participantes se organizem neste sentido e informando por meio dos cursos as possibilidades existentes nas regiões onde são realizados. $\mathrm{Na}$ cidade de João Pessoa/PB, por exemplo, mulheres que participaram do programa foram incorporadas pela Associação dos Pescadores da comunidade, compondo o grupo de marisqueiras. As mulheres afirmaram em depoimento que desejavam organizar uma cooperativa independente de marisqueiras e artesãs na região. 


\section{Trabalhonecessário}

Issn: $1808-799 X$

ano 14, número $24-2016$

Algumas delas também reforçaram terem se direcionado posteriormente para o curso de Recursos Pesqueiros, oferecido no Instituto Federal naquela cidade, na modalidade Jovens e Adultos (BRASIL, 2011c, p.73-74), em busca de capacitação técnica para a organização da cooperativa. Ainda assim, as mulheres relataram que os rendimentos eram baixos, como no caso das marisqueiras, que afirmaram receber $\mathrm{R} \$ 15$ por dia de trabalho, descontados os custos da cooperativa.

Observamos que em algumas regiões ocorreram experiências de fortalecimento de cooperativas já existentes, por meio de mulheres que foram buscar no Programa Mulheres Mil qualificação relacionada ao trabalho que executavam. No entanto, não constatamos nenhum relato de experiência que apresentasse a criação de uma nova cooperativa a partir do curso oferecido pelo Programa, semelhante às incubadoras universitárias de cooperativas populares. $\mathrm{A}$ maior parte dos relatos indica que as mulheres se direcionaram em busca de emprego em cooperativas ou buscavam qualificação técnica para aprimorarem o trabalho que já exerciam.

Consideramos que é preciso investigar como e se estas mulheres deram continuidade ao trabalho em cooperativas e se continuaram os cursos. etc., aprofundando a coleta de dados, em especial nas regiões que ofereceram os cursos após o final do projeto piloto.

\section{Considerações finais}

O Programa Nacional Mulheres Mil oferece qualificação profissional de curta duração a mulheres pobres e incentiva a organização de cooperativas de trabalho, mas durante sua execução não coloca em questão as condições nas quais se desenvolve o cooperativismo no país, tomando-o como uma solução eficaz para o desemprego. Não é apresentado a essas mulheres um mapa do cooperativismo nas diferentes regiões do país, com as possibilidades de engajamento, nem mesmo um diagnóstico sistematizado das condições objetivas 


\section{Trabalhonecessário}

Issn: $1808-799 X$

ano 14, número $24-2016$

de organização de mulheres em cooperativas e do mercado de trabalho das regiões nas quais se desenvolvem os cursos. Ao final do curso, também não há um projeto de apoio técnico e financeiro para que elas organizem estas cooperativas. Como incentivar mulheres em situação de pobreza, com baixa escolarização, a organizar autonomamente cooperativas de trabalho? O curso de qualificação oferecido durante um ano é suficiente para se alcançar este objetivo? Estas são uma questão pouco abordadas pelos documentos que orientam o programa.

Muitas mulheres desempregadas têm filhos e vivem em regiões onde não há creches públicas suficientes para atender a demanda das famílias. $O$ Programa Mulheres Mil não procura se articular a iniciativas neste sentido. A Pesquisa Nacional por Amostra de Domicílios (PNAD/IBGE) 2012, mostrou que dentre 10.784 milhões de crianças entre 0 e 4 anos, somente 3.969 milhões frequentavam a pré-escola. A mesma pesquisa demonstrou que dentre 79.129 milhões de mulheres em idade ativa, somente 43.413 milhões eram economicamente ativas na semana de referência da pesquisa. Ainda que existam esforços no sentido de solucionar 0 insuficiente atendimento de crianças pequenas em creches, com programas como o Brasil Carinhoso (Resolução CD/FNDE/MEC ํo 19, de 29 de setembro de 2014), este problema não foi resolvido nos últimos anos, configurando-se como um dos fatores que faz com que as mulheres não procurem programas de qualificação profissional ou evadam durante os cursos. Trata-se de um problema de infraestrutura pública e as mulheres não podem ser responsabilizadas por isso.

Os projetos criados no interior do Programa Brasil Sem Miséria parecem não ter uma articulação adequada, deixando muitas lacunas que poderiam ser solucionadas por um planejamento fundamentado nas necessidades da população atendida. O curso de qualificação profissional não pode estar separado do oferecimento de creches, bolsas adequadas ao custeio de transporte e alimentação das estudantes, capacitação técnica para a organização de cooperativas, etc. Esta desarticulação dos programas é um dos elementos que 


\section{Trabalhonecessário}

Issn: $1808-799 X$

ano 14, número $24-2016$

constitui o desinteresse dos profissionais dos Institutos Federais em participar do Programa Mulheres Mil, pois os objetivos enunciados - aumento da escolarização e organização de cooperativas de mulheres - não podem ser realizados nas atuais condições.

Além disso, o público a quem se destina o programa é composto por mulheres que geralmente são as responsáveis pelos serviços domésticos, muitas vezes executando todo o trabalho necessário para a manutenção da família e cuidando das crianças sozinhas. O trabalho de empregada doméstica sem contrato, por exemplo, é uma solução viável para o desemprego encontrada por estas mulheres, pois podem ser empregadas intermitentes ou trabalhar em meio período. Esta dinâmica não pode entrar em consonância com aquela dos cursos, mesmo daqueles de curta duração.

Ainda que existisse uma maior disposição dos Institutos Federais em realizar projetos como o Mulheres Mil, direcionado a um público diferente daqueles que ocupam os cursos técnicos e tecnológicos, a ausência de incentivos financeiros e subjetivos adequados, os espaços insuficientes para a realização de cursos de qualificação profissional, a separação entre a qualificação profissional e a organização de cooperativas, são elementos que impedem o cumprimento dos objetivos enunciados. O programa não dá centralidade às demandas regionais de emprego das mulheres ou às demandas das cooperativas já existentes nas diferentes regiões. Não é uma política pública de qualificação profissional vinculada à economia solidária que, necessariamente, fortalece as trabalhadoras que já estão organizadas e que, muitas vezes, precisam de maiores e melhores subsídios aos seus projetos. O que poderia acarretar a agregação de novas trabalhadoras cooperadas.

Além disso, o Mulheres Mil não promove de fato o aumento da escolarização e a ampliação do conhecimento técnico das trabalhadoras, pois oferece somente a qualificação profissional básica, deixando às mulheres a responsabilidade pela continuidade da escolarização e da formação profissional. 


\section{Trabalhonecessário}

Issn: $1808-799 X$

ano 14, número $24-2016$

\section{Referências}

CATTANI, Antônio David. Desigualdades socioeconômicas Brasil/Canadá: um estudo a partir de extremos. Interfaces Brasil/Canadá, Rio Grande, n. 6, 2006.

LEITE, Márcia. A economia solidária e o trabalho associativo: teorias e realidades. Revista brasileira de ciências sociais, vol.24, №. 69, fevereiro, 2009.

LIMA, Jacob. Trabalho informal, autogestionário e gênero. Sociedade e cultura, v.9, n.2, julho/dezembro 2006, p.303-310.

BRASIL. Ministério da Educação. Memorando de entendimento para a colaboração na área de educação profissional científica e tecnológica entre o Conselho Nacional das Instituições da Rede Federal de Educação Profissional e Tecnológica (CONIF) e a Associação de Faculdades Comunitárias Canadenses (ACCC), 2010.

BRASIL. Ministério da Educação. Mulheres Mil na Rede Federal: caminhos da inclusão. Brasília, março de 2011a.

BRASIL. Ministério da Educação. Mulheres Mil: artigos e relatos. Brasília, 2011b.

BRASIL. Ministério da Educação. História mil das mulheres mil. Brasília, 2011c.

BRASIL. Ministério da Educação. Guia metodológico do sistema de acesso, permanência e êxito. Brasília, 2011d.

ROSA, Stela (org). Mulheres Mil: do sonho a realidade $=$ Thousand women: making dreams come true = Miles Femme: du revê à la realité. Brasília: Ministério da Educação, 2011.

Recebido: 18 de junho de 2016

Aprovado: 19 de julho de 2016 